\title{
Research on the Aesthetic Value of Celebrity Sculpture in Landscape
}

\author{
Na Bao \\ College of humanities, Qujing Normal University, Yunnan, 655011, China \\ 358693978@qq.com
}

Keywords: landscape; celebrity sculpture; aesthetic value

\begin{abstract}
Sculpture in the landscape can not only make the finishing point, but also can beautify the environment, as a unique art form, promote the interaction between man and the environment, and play an art aesthetic role in the landscape art space. In the landscape, increasing the participation of sculptures can make the landscape more humane, get rid of the cold purely functional image, and open up new space for development. This paper mainly analyzes the classification of celebrity sculptures, analyzes the current landscape design to find out the aesthetic value of the sculpture in the landscape, and shows the celebrity's message to be represented.
\end{abstract}

\section{Introduction}

Almost all public places in the city can see the presence of contemporary celebrity sculptures. In addition to decorating the urban environment and promoting the main theme, relevant government departments have also begun to pay attention to celebrity sculpture as an artist's subtle influence and influence on the public. The recognition of the famous celebrity sculptures of the United States as a propaganda vehicle for the protection of the environment has led to the awakening of public awareness of modern citizens [1]. The attention to public art will inevitably promote the development of contemporary celebrity sculpture. In the modern landscape, celebrity sculpture is not only an indispensable part of the landscape, but also plays a crucial role in the landscape. Celebrity sculpture is an artificial art. The charm of landscape mainly embodies a form of beauty [2]. With the continuous development and innovation of art and the progress of the times, people's aesthetics have also undergone great changes. In modern landscapes, celebrity sculpture is not only a kind of decoration, embellishment, but also a new type of landscape. The image is an embodiment of beauty that blends in with the landscape, a spiritual symbol [3].

Successful celebrity sculpture can achieve the aesthetic education effect of public art, but the more basic and universal role of celebrity sculpture is to create a good environment, form a good atmosphere, and satisfy people's spiritual pursuits. Celebrity sculpture is built for the city. The city is built by people. The roots are found, and all material wealth and spiritual wealth created by mankind ultimately serve humanity. Celebrity sculpture is no exception. The development of modern economy 
and science and technology has caused the popular spirit to be depressed, the heart is empty, and the wandering city soul cannot find the harbor where it is parked. Citizens have more intense desires and higher demands on the spirit, and appreciate the subject's aesthetic standards and requirements [4].

\section{The Aesthetic Significance of Celebrity Sculpture}

\subsection{The aesthetic significance of sculpture ornamental space}

Sculpture is a three-dimensional modeling art. Its creation itself takes care of all kinds of viewing angles. The art form that takes the initiative to enter the masses requires citizens to provide a full range of viewing space. Sculptures are placed in a rational layout that conforms to three-dimensional sculpture and possess reasonable virtual Space, all-round dissemination of its artistic atmosphere, so that the public can easily obtain the corresponding information. Celebrity sculpture design is all-encompassing. The lower part of the work has the names of the characters and a brief introduction to the characters. It allows citizens to easily understand the simple deeds of cultural celebrities, combined with the design of the works to deepen their literary accomplishments and artistic positions. However, many celebrity sculptures in the square are backed by walls and partially concealed the characters. The sculptures of Mr. Ba Jin and Mr. Bing Xin in the square are back to back, and it seems that the two literary giants are waiting outside the rubbish stands erected in iron frames. There was also a group of human sculptures in the square that was also successful, but it was placed on top of two opposing buildings and surrounded by luxuriant bamboo forests. I wonder if this arrangement is related to "spring", "summer", "autumn", The tulle of "Winter" waist is different from the celebrity sculpture space and the public is also a problem of contemporary celebrity sculpture [5].
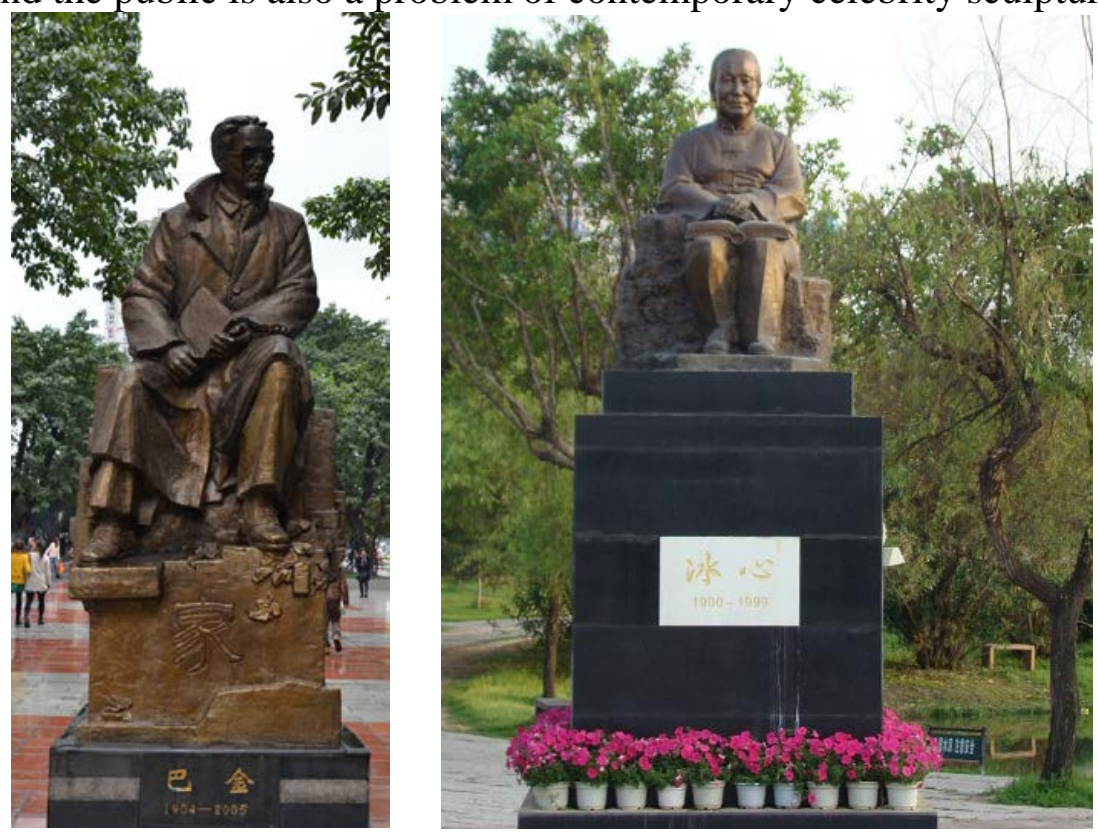

Fig. 1 The sculptures of Mr. Ba Jin and Mr. Bing Xin

\subsection{The relationship between sculpture volume and environmental space aesthetic significance}

The volume and scale of the sculpture can convey a wealth of information, and the size of the body should be taken into account when designing the sculpture. The volume of the sculpture must not only match with the theme of the white expression, but also bear the meaning of its own, but also match the 
surrounding environment and atmosphere. As a part of the urban landscape, celebrity sculptures must avoid affecting the function of the original environmental space. The sculptures in the mall rest area do not pay attention to all-round coordination. Celebrity sculpture should have added footnotes to the city, and it has its own visual comfort. The premise, but the existence of the sculpture brings inconvenience to people's lives, eliminating the value of its existence[6].

\subsection{Aesthetics and harmonious aesthetic significance of artistic conception}

The theme and form of celebrity sculpture is effectively integrated with its environment. Naturally, it will create its unique artistic conception and create a unique atmosphere. Due to the lack of overall planning, many contemporary urban plans do not allow space for celebrity sculptures, which can only play a role of embellishment and fillers. As a result, some of the sculpture themes do not harmonize with the surrounding environment, and even destroy the overall sense of the environment, or The atmosphere created by neighboring two green spaces is completely different and lacks a sense of unity and coordination. Not only the form of the celebrity sculpture has a great relationship with its setting environment, but the subject and subject matter of its creation are also closely related to the city it exits from.

\section{Intrinsic Value of Celebrity Sculpture Aesthetics}

\subsection{Show the inner spirit of celebrity sculpture}

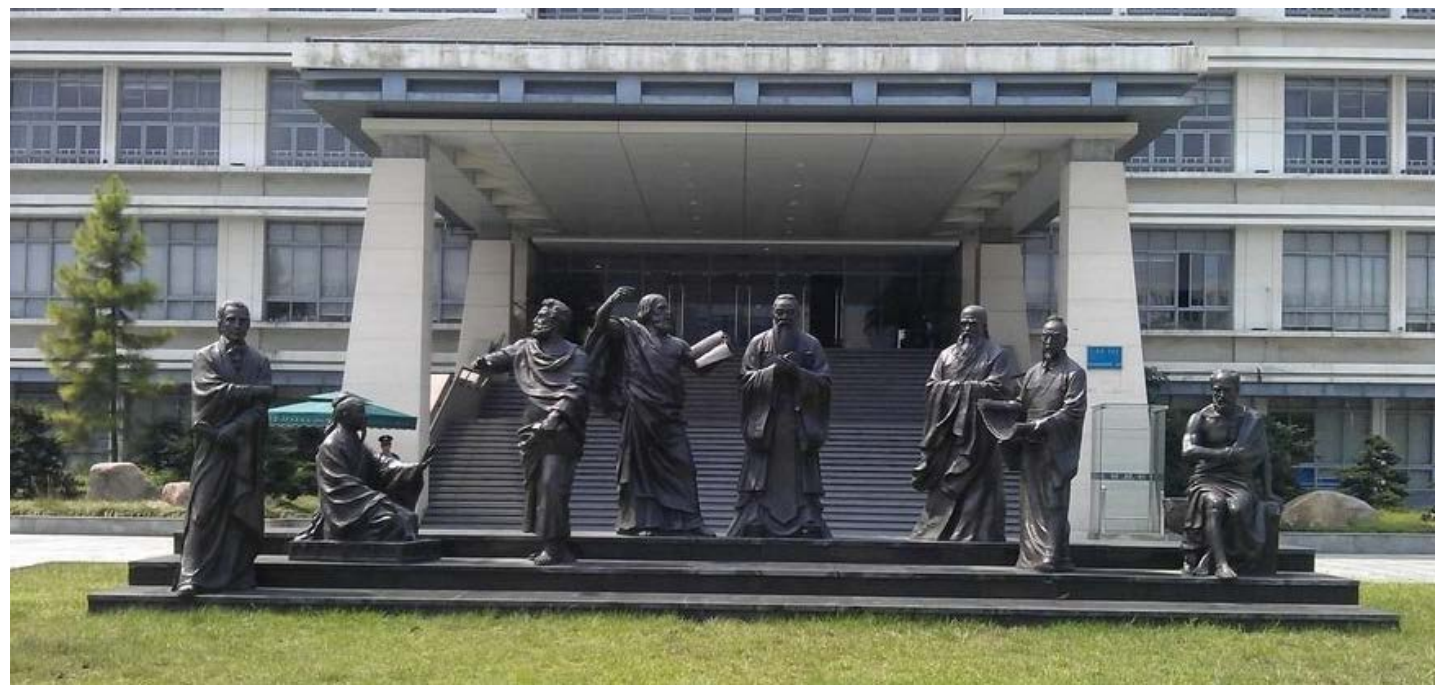

Fig. 2 Show the inner spirit of celebrity sculpture

The spirit refers to the human consciousness. It is an external manifestation of human thinking activity and psychological condition. The spirit is not only a universal rational expression, but also a kind of intrinsic practical expression of behavior. To explain it in one sentence, the meaning of the spirit can be summarized as the essence of being free and spontaneous. In the process of creating celebrity sculptures, the spirit is indispensable, because history has proved that it can make the celebrity sculptures show the celebrity's rationality and practicality, that is, their dedication to works can shock people. When celebrity sculptures are created, they must master the soul of celebrity figures in a comprehensive and profound manner. Only by grasping the mental outlook of celebrity figures, can they better reflect the essential characteristics of celebrity figures, and consider where the characters are when they are created. The background of the times and the characteristics of the local 
environment must also be integrated into the common mental outlook of the people of the author's time, because the author must certainly intentionally or unintentionally integrate his soul into the work during his work. Spirit is the soul of a person. If a person does not have a soul, then the person is like a dead corpse. Celebrity sculptures are more concerned with the spirit. If celebrity sculptures do not have the spirit of the celebrities they represent, then this statue is like iron and iron and worthless. The spirit has given celebrity sculpture life. Only by firmly grasping the inner spirit of celebrities can we not be objectively red taped in the creative process. Only when we are doing our own use of things can we sculpt new ideas in creation. Works show the inner spirit through sculpture.

\subsection{Express the language of managers through celebrity sculptures}

In the creation of celebrity sculptures, the inner spirit is the form language of the characters. The relationship between celebrity sculpture and inner spirit is just like people's appearance and words and deeds. The inner spirit can reveal people's soul. Once this soul is created, it will inevitably arouse the resonance of residents. The evolution of formal languages among celebrity sculptures has made celebrity sculptures colorful. This varied and varied work has attracted everyone to appreciate and analyze the spiritual world of people from different regions, nationalities, and strata. It can be said that the spirit is the soul of celebrity sculptures. The formal language is the bones and skins of celebrity sculptures. The celebrity sculptures can only make full use of the formal languages of the characters to create a distinct style and flesh. Formal language determines the quality of the author's work, but also fully reflects the author's talent and skills. Only by taking a bold approach after grasping the inner spirit of the portrait can we find the most suitable formal language for celebrity sculpture.

\subsection{Celebrity sculpture object form beauty}

Both celebrities and ordinary people have their own personal characteristics. Everyone has their own body, appearance, hairstyle and clothing preferences. When celebrity sculptures are created, they cannot naturally depart from the inherent characteristics of these people and celebrity sculptures. When creating, we must follow the characteristics of the character's life habits, occupational characteristics, personal experience, and hobbies. Only through the study of the unique and objective forms of these characters can the authors obtain more specific information in the creation of portraiture. Detailed information can be used to discover the different qualities of the characters. In this way, people's portrait sculptures can become more representative.

\subsection{Relationship between Celebrity Sculpture and Creators Celebrity Sculpture}

Creation not only expresses only the cultural connotation represented by the character and its distinctive spiritual image, but also the emotional expression of the creator himself. Whether or not the spirit is grasped accurately is the key to the success or failure of the creator in the creation process of the celebrity sculpture. The creators often have an understanding and interpretation of the characters they want to express themselves. The depth of the creator's knowledge of the characters depends on the creator's own world view, values, other aspects of knowledge, and life experience. These require the creators to slowly accumulate after long-term efforts. The writer's sensibility and understanding are related to the success or failure of celebrity sculpture. In addition to the author's deep understanding of the characters, the creators need to be as familiar with the characters as possible and fully understand the aspects of the characters. After the creator's subjective emotions and 
aesthetic performance of the characters, and the pressure brought by the works for all aspects, the change of their mindset will affect the creation of celebrity sculptures.

\section{The Aesthetic Value of Sculpture in Landscape Design}

In the process of designing celebrity sculptures, sculptors should make full predictions and analysis of the size and size of the sculpture in advance, and when necessary, they should also perform light-transmission processing and illusion correction. Celebrity sculptures are fixed displays in different landscapes. Therefore, they limit people's viewing conditions. If viewers want to fully experience the aesthetic beauty brought by sculpture and appreciate its aesthetic value, they must Watch through different angles and distances. The best viewing distance is twice or three times the height of the sculpture. This is more suitable for a comprehensive view. If you want to see more clearly, you need to double the height of the sculpture. In order to allow viewers to appreciate the beauty brought by sculpture.

\subsection{The sculpture should show the texture of the texture}

Originally refers to the texture of the skin, and the texture of the material mainly refers to the natural and unstructured texture, that is, the texture of the material itself and the texture of the slightly carved, that is, the natural texture of the material that does not destroy the material. It shows that the master craftsmanship and natural beauty are conscious creations. In the sculptural form, the body is the most basic element. The texture adheres to the shape of the sculpture, conceals the artist's perception of the material and rich creative behavior, and controls the artist's unique control over the special material. Texture is the language of sculpture. It conveys the artist's emotions. It is the trace of the artist's production of sculptures and conveys the emotions and thoughts created by the artist. It is the artistic feature of sculpture works, reflects people's artistic ideas and aesthetic taste, and the texture is the sculpture and landscape environment. The high degree of unity, sometimes exploration of the material and the sense of form if it is out of the construction of specific feelings, it will be difficult to avoid the end.

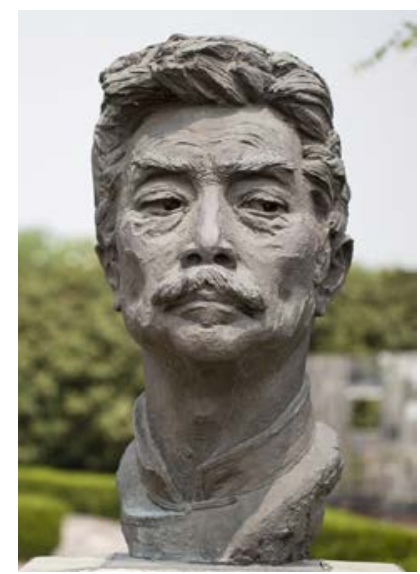

Fig. 3 The celebrity statue details the texture of the texture

\subsection{Sculpture should show the beauty of color life}

The color of sculpture is able to meet the psychological aesthetic needs of modern people, and to achieve the same with the landscape environment, so that the sculpture art is full of a new spirit, resulting in the infinite tension of sculpture. The style, scale, and materials of the sculpture are all in 
harmony with the surrounding environment. It uses the color and texture of natural materials as well as natural dyes, paints, and colorants to create a coordinated color environment. The color of the sculpture implies the power of life, conveying emotions and warmth to people, bringing people's thinking and emotional changes, and at the same time brings a certain psychological effect, using various means to break through the visual order of people and make the artist's creativity. There is emotional meaning and spiritual content.

\subsection{The sculpture should exhibit ecological beauty}

In the design of the sculpture, he also participated in the ecological battle, using natural methods to allow the sculpture to "breathe" and build a healthy space environment. Considering the local characteristics of the ecosystem, the intervention of foreign materials is reduced in the landscape modeling. The material of the sculpture uses the materials in the original ecological environment as much as possible, which can better reduce the damage to the original ecosystem. In the design of sculptures, materials and weather-adapted designs are used to adjust the temperature, air flow and moderation, so that sunlight can directly shine on sculptures, reduce artificial lighting, reduce light pollution to the ecology, and create a healthy living environment. The location, location and construction of the sculpture should take into account adequate protection of renewable resources and reduce dependence on non-renewable energy sources. Through the artistic conception of production of domestic garbage, organization and organization of modern sculptures, it is necessary to demonstrate the beauty of creation, but also to remind the public of the concept of the environment. Use non-toxic, non-polluting, sustainable and renewable materials and products, reduce environmental and social losses, and enhance biodegradable or recycled use. Planting trees and flowers around the sculpture, designing the water circulation around the sculpture, collecting, storing, and using rainwater makes the sculpture an important part of the local landscape modeling biological system.

\subsection{The sculpture should show the harmony beauty in the environment}

Sculpture works should have a simple ecological concept, responsibility for nature, the environment, and ecology, as well as the harmonious development of people and the ecological environment, and the values of people and nature. An infectious landscape sculpture must not only have a rich and vivid form, but also have a healthy and active theme, not the concept of reasoning. The successful sculptures do not lie in the size, but in the common integration of materials, techniques, and the environment, as well as the overall visual beauty. When applied properly, they will add brilliance, and vice verse. The decorative nature of celebrity sculptures can beautify the environmental space, satisfy people's psychological needs for beauty, and demonstrate the aesthetic and pleasing beauty of landscape design works as well as the ideological and political nature of sculpture. The celebrity sculptures we see in real life are abstract or semi-abstract works, and they give a certain decorative effect to the green space environment through craftsmanship or interest.

\subsection{The sculpture should show the spirit}

Sculpture can make the spirit of the work reach the extreme and meet people's aesthetic needs, so that the author is easy to express, the audience is easy to accept. Sculpture not only embodies the author's artistic ideals and life experiences, he also pays attention to ecological principles and human visual psychology, strengthens the rhythm of sculpture modeling and environment formation, and is also in line with people's needs, and is conducive to comforting and adjusting people's psychological 
tension in the city. Evoke beauty of life and people's yearning for ideal life. A good landscape celebrity sculpture can not only satisfy people's aesthetic needs, improve people's spiritual quality, but also can penetrate into the public's life, adjust public attitudes, coordinate public relations and public culture, and make people in modern city life, psychological structure. Changes in psychological factors have made it possible for people to achieve a harmonious life and development. This is also the ultimate goal of aesthetic appreciation. The integration of the humanistic spirit and the environment has formed a humanistic environment. The role of sculpture in the landscape is an important manifestation of the humanities in the city. With a unique artistic language, each concept in the landscape is expressed, conveying unique aesthetic standards and values for people and guiding and educating people's spiritual world.

\section{Conclusion}

It can be seen that landscape modeling and sculpture itself are interdependent. Art comes from the end of language. At this point, sculpture is extremely significant. The value of sculpture lies in its profound content, visual pleasure, and the richness and persistence of the experience that follows. Like all other arts, the true value of sculptures comes from cultural progress and promotion. Without the deep understanding and exploration of the laws of the sculpture itself, it loses the possibility of creativity. This kind of inquiry involves the perception of various direct and indirect Related things, the study and analysis of tradition, the formation of celebrity sculpture language and performance techniques.

\section{Acknowledgments}

Foundation project: Qujing Normal University 2018 school research special research project: the landscape design of the sculpture group of Tao Sheng square, Qujing Normal University (2018ZX007)

\section{References}

[1] Zhang Shun, et al. Aesthetic research of environmental sculpture art. Northwest A\&F University, Vol. 10 (2009) No. 35, p.378-382.

[2] Liu Zhicheng, et al. Research on aesthetic psychological form of characteristic landscape. Huazhong University of Science and Technology, Vol. 12 (2008) No. 35, p.125-129.

[3] Peng Zunshan, et al.The Artistic Conception of Sculpture in Urban Park Environmental Art. Journal of Shangrao Teachers College, Vol. 2 (2007) No. 35, p.169-174.

[4] Chen Shaoqing, et al. Research on the aesthetic characteristics of landscape features in urban planning. Huazhong University of Science and Technology, Vol. 6 (2008) No. 35, p.39-45.

[5] Hui Shumei, et al. Environment People. Sculpture Talking about Celebrity Sculpture in China. Journal of Xuzhou Institute of Education, Vol. 4 (2004) No. 35, p.214-221.

[6] Zhu Jie, Huang Mingshun, et al. Here and Now • This Scene• At this Time City Discussion on the Design of Squares. China Landscape Modeling, Vol. 5 (2006) No. 35, p.312-316. 